\title{
A Novel Process to Form Al-12 mass\% Si Bulk Material from Machined Chips using Bulk Mechanical Alloying
}

\author{
Tachai Luangvaranunt*, Katsuyoshi Kondoh and Tatsuhiko Aizawa \\ Research Center for Advanced Science and Technology, University of Tokyo, Tokyo 153-8904, Japan
}

\begin{abstract}
A novel process for recycle technology has been developed for materials in form of chip. Machined chips of Al-12 mass\%Si alloy were used to demonstrate the effectiveness of the process in producing high strength material with refined microstructure. The process involves Bulk Mechanical Alloying (BMA), preheating and forging. Both primary and eutectic Si particles were refined by repeated extrusion during BMA. The tensile and hardness properties of the materials depend on the Si particle size and the thermal history. The Si particle size is governed by the number of BMA cycle, while the hardness of the alloy depends on the preheating condition. For alloy produced by BMA 500 cycles and preheated at $773 \mathrm{~K}$ for $10 \mathrm{~min}$, the tensile strength and Rockwell hardness reaches $431 \mathrm{MPa}$ and $81 \mathrm{HRB}$ respectively. Energy consumption of BMA process is $13.6 \mathrm{~kJ} /$ cycle. For BMA 200 cycle, specific energy consumption is $136 \mathrm{MJ} / \mathrm{kg}$.
\end{abstract}

(Received January 30, 2002; Accepted March 7, 2002)

Keywords: eutectic aluminium-silicon alloy, recycle processing, bulk mechanical alloying, machined chips, energy consumption

\section{Introduction}

Aluminum alloys exhibit high strength to weight ratio due to the low specific density. They are increasingly replacing irons, steels, and plastics in many engineering applications, ranging from structural and mechanical parts in automobiles to light weight housing of handheld electronics. Comparing with engineering plastic and composites, which also process high strength to weight ratio, the major advantage of Al alloys is their recyclability. New and old scraps of Al alloys can be used as raw materials to produce a new product with no or little degradation of materials quality. Prime example is the closed-loop product recycling in beverage cans industry. More than $80 \%$ of used beverage cans are returned directly to the primary producer, to be melted with adjustment of the composition, and finally become feedstock for producing new can sheet. ${ }^{1)}$

A major category of recycled material is the by process scraps from manufacturing processes. They are usually regarded as dross, refuse, machined chips, flakes, etc. Some of these are recycled in-house to remelt furnace or sold to a secondary operator. However, additional cost is incurred when contamination and extraneous metals in the recycled materials are unavoidable, especially when $\mathrm{Al}$ alloys parts are attached to another components in the final fabrication stage of a product. Problems of composition and impurity control bring about inefficiency of recycling process. Loss of metal during melting stage, a.k.a. melt loss, goes to the skim. A $20 \%$ melt loss to the untreatable skim and dross is not unusual. ${ }^{2)}$ Current recycling technology of Al alloys includes scrap collection and preparation, and remelting. Reverbatory and open-hearth furnaces are the predominant remelting facilities. ${ }^{1)}$ A substantial metal loss occurs due to the formation of protective oxide film covering and protecting the rest of the melt from furnace atmosphere. Additional step for refining, and the upgrading of molten metal to a ready-to-cast is done to maintain the alloy integrity. This involves the use of flux or slag, which consequently produce toxic fume and increase environmental burden.

This paper presents Bulk Mechanical Alloying (BMA) as a materials processing method able to make use of recycled material, and consequently to lessen environment burdens. A barrier-free process is necessary for sustainable and efficient use of recycled materials. ${ }^{3)}$ A direct connectivity between the input materials and the output product must be realized. For a demonstration, Al-12 mass \% Si alloy in the form of machined chips have been used as input materials for producing a highperformance alloy.

\section{Bulk Mechanical Alloying}

BMA is based on plastic deformation of materials by repeated rapid extrusion. It is a cyclic process; one cycle of BMA consists of one extrusion stage and two compaction stages in an extrusion die assembly. The BMA machine is an $800-\mathrm{kN}$ hydraulic press run according to the pass schedule of punches in a die, schematically shown in Fig. 1. With the current setup, the extrusion ratio of the die cavity is 1.44 , which is $\phi 30 \mathrm{~mm} / \phi 25 \mathrm{~mm}$. Relative density during BMA is controlled to $80 \%$ for ease of extrusion and compaction stages. Paraffin powder with an amount equivalent to 1 mass $\%$ was mixed with the input material, as well as 3 drops of liquid paraffin was added into the die cavity every 60 cycles as a lubricant to reduce friction loss. The die was forced cool to keep the temperature under $333 \mathrm{~K}$, and shielded with Ar gas to prevent any oxidation during processing. An inline computer monitored the punch load and position enabling calculation of energy consumption of each BMA cycle. The punch speed is $13 \mathrm{~mm} / \mathrm{s}$, and one cycle of BMA is finished in $9 \mathrm{~s}$. During the process, large amount of plastic deformation and shear flow continuously induce mixing and homogenization of the input materials. Details of the BMA process were reported elsewhere. ${ }^{4,5)}$ 
(1) Compaction
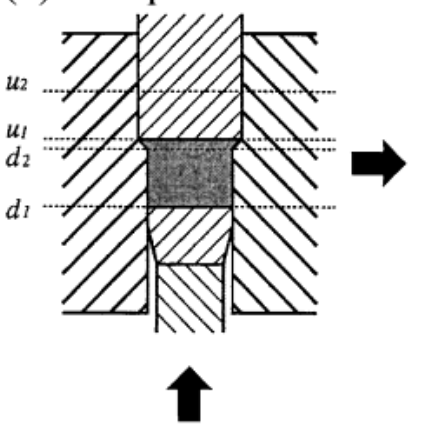

(6) Extrusion
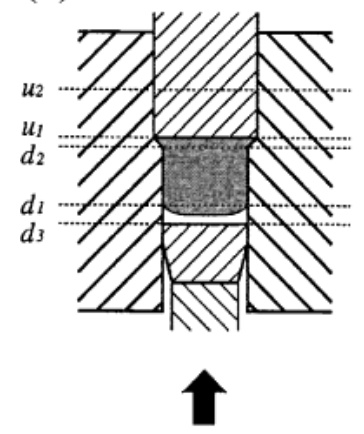

(5) Withdrawal

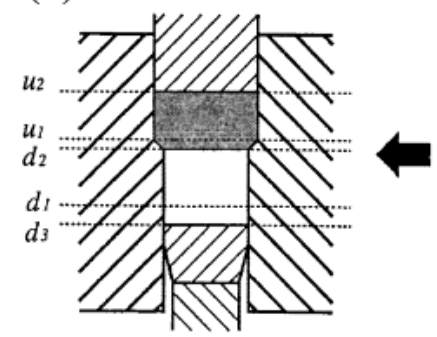

(2) Withdrawal

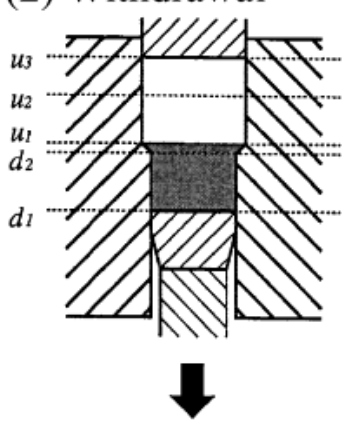

(3) Ejection

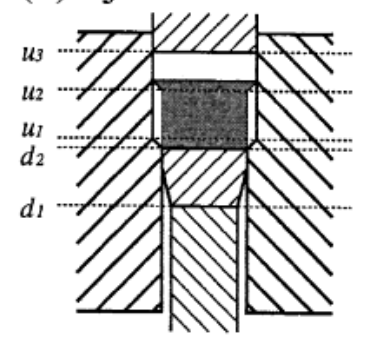

$\checkmark$

(4) Compaction

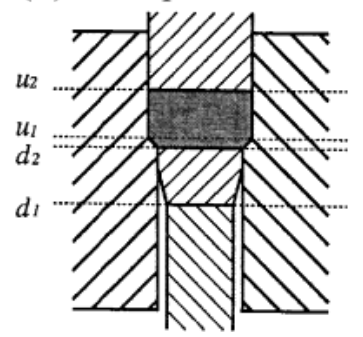

Fig. 1 Pass schedule of punches in die assembly for 1 cycle of BMA.

\section{Experimental Procedure}

Machined chips of Al-12 mass\%Si alloy (JIS AC3A) were used as input materials. They were rinsed in acetone to remove any machine grease, and then dried in air for 5 hours. The cleaned chips are subsequently subjected to BMA, cold compact, rapid preheating and then forging. The BMA was done for 100, 200 and 500 cycles. At the last cycle of BMA stage, the material is cold compacted in BMA die under $566 \mathrm{MPa}$ to $\phi 30 \mathrm{~mm}$ diameter. The cold compacted sample was preheated from room temperature to $773 \mathrm{~K}$ at heating rate of $4 \mathrm{~K} / \mathrm{s}$, and hold at the temperature for 2, 10, 20 and $30 \mathrm{~min}$. Rapid heating was achieved by employing ULVAC Infrared Image Furnace with flow of $\mathrm{N}_{2}$ gas to minimize oxidation. Heated sample was quickly transferred to a $1000-\mathrm{kN}$ forging press, and was forged under $816 \mathrm{MPa}$ at initial strain rate of $2.9 \mathrm{~s}^{-1}$ to a $\phi 35 \mathrm{~mm}$ billet. The forging die temperature was held at $523 \mathrm{~K}$ causing the temperature of the billet at forging to drop about $100 \mathrm{~K}$ lower than the preheating temperature. After forging, the billet was chilled on a large steel plate. Bone shape tensile specimen having a gage length of $14 \mathrm{~mm}$ and a diameter of $\phi 3.5 \mathrm{~mm}$ was machined from the middle part of the billet in the direction perpendicular to forging axis. Figure 2 shows flow chart of the materials fabricated

from wasted chips to full density billet. Microstructure, microvickers hardness, Rockwell hardness and tensile strength of both as-BMAed compact and forged billet were investigated. Scanning electron microscopy (SEM) was employed to examine the fracture surface of tensile specimen.

\section{Results and Discussion}

Full density Al-12 mass\%Si bulk material was successfully produced from machined chips. The properties of the alloy after each process step, namely as-BMAed and forged, are described in order to characterize the effect of each process step on the final properties of the alloy.

\subsection{Properties of as-BMAed compact}

Figure 3 shows microstructure of as-BMAed samples, as compared with that of the machined chips. The microstructure of the material after BMA for 500 cycles, Fig. 3(c), consists of both large Si particles having size in less than $10 \mu \mathrm{m}$ range and the ones having size in sub-micron range. The observed largest Si particle size decreases with increasing number BMA cycle, as shown in Fig. 4. Typical Al-Si alloy fails by cracks originated at large Si particle. ${ }^{6}$ Decreasing of $\mathrm{Si}$ particle size is known to improve mechanical properties of the alloy. ${ }^{7)}$

During extrusion stage, large amount of stress is applied to the material, inducing flow, fracturing, and plastic deformation of material. By adjustment of pass schedule of the punches and the amount of input material, relative density of the material during processing can be controlled. The relative density during processing is kept at $80 \%$ for ease of extrusion while maintaining a large stress state applied to the materials. A lower relative density is less effective in refining the $\mathrm{Si}$ particles. A higher relative density causes difficulty of extrusion at room temperature. Optimal relative density allows fracturing and movement of Si particles.

Al matrix is able to endure greater amount of plastic deformation than Si phase; therefore, fracturing in Si phase occurs with work hardening accumulates in $\mathrm{Al}$ matrix. Gradient of deformation builds up due to the difference in deformation behavior of the two phases. Geometrically necessary dislocations are stored in the $\mathrm{Al}$ phase to accommodate this deformation gradient, and provide the internal stresses which are necessary for simultaneous compatible deformation of the two phases. ${ }^{8)}$ The presence of geometrically necessary dislocations enhances work hardening of particle reinforced aluminum alloy. The finely dispersed Si phase provides a large number of sites of geometrically necessary dislocations. Moreover, work hardening is a strong function of interparticle distance, increasing with decreasing interparticle distance, particularly when interparticle distance is less than $10 \mu \mathrm{m} .{ }^{9)}$ The materials containing finer Si particles, with inherent smaller interparticle distance, work harden at a higher rate than the materials containing larger Si particles. Microvickers hardness of as-BMAed samples in Fig. 5 shows the increase in hardness with increasing the number of BMA cycles. The presence of sub-micron Si particles may also contribute to work hardening of the alloy through Orawan's mechanism of dispersion hardening. ${ }^{10)}$ To summarize, the increase in hardness may due to both the increasing work hard- 


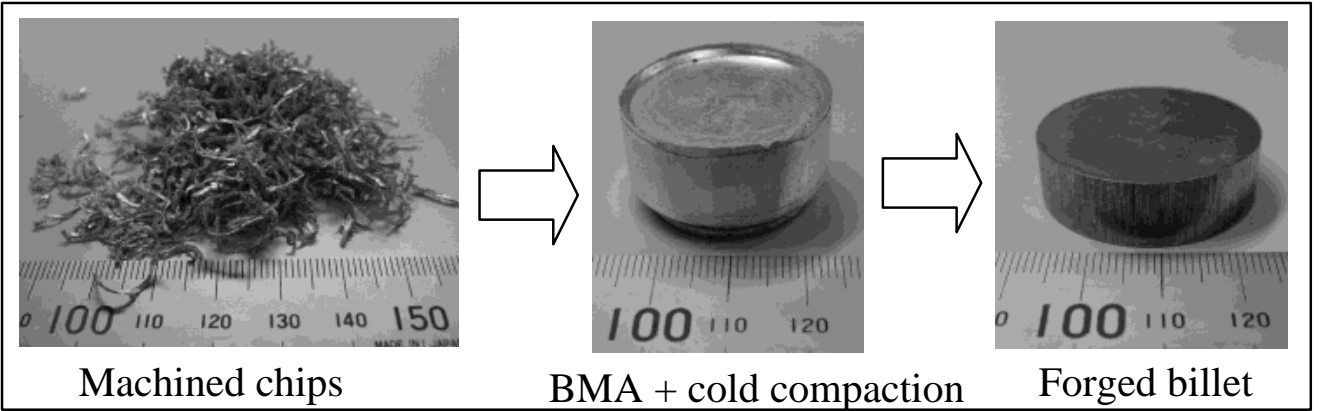

Fig. 2 Flow chart of processed material from machined chips to final product.
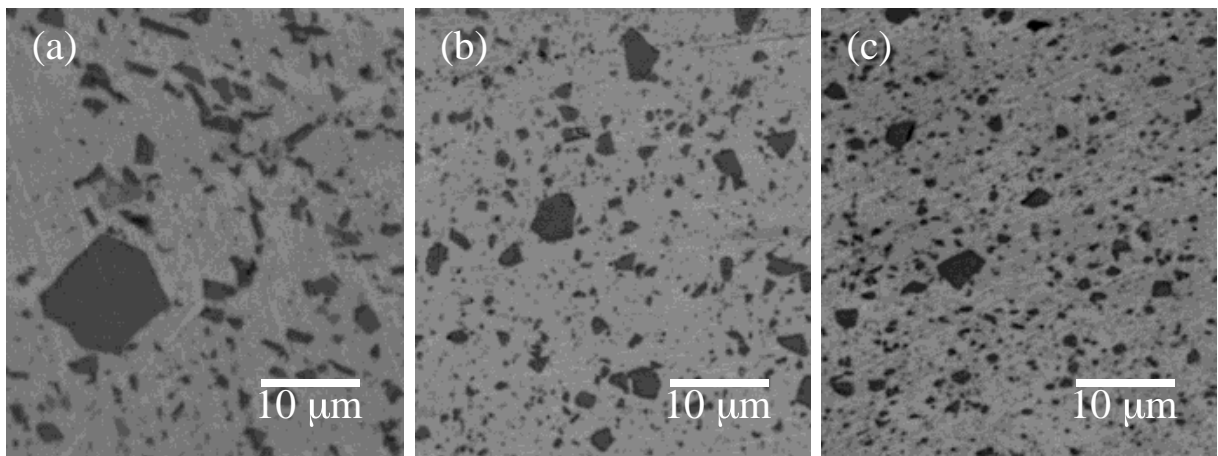

Fig. 3 Microstructure of Al-12 mass\%Si alloy (a) machined chips, (b) BMA 100 cycles and (c) BMA 500 cycles.

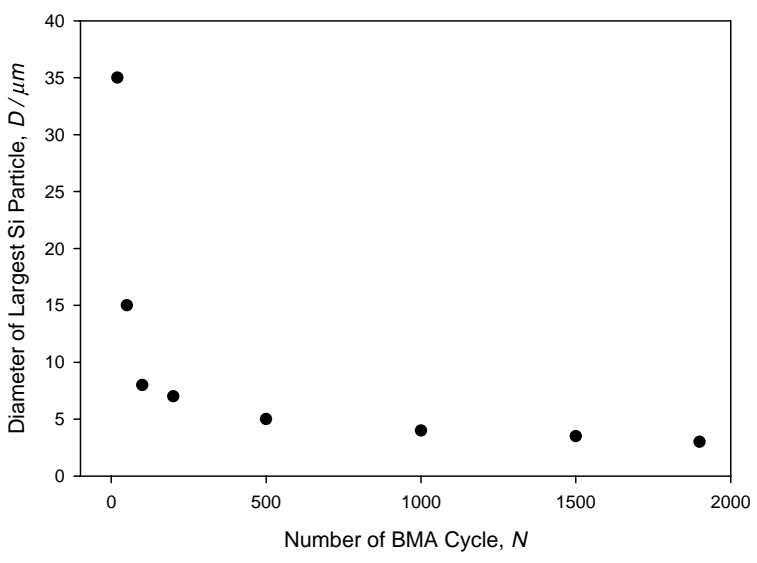

Fig. 4 Refinement of Si particles size as BMA progresses in as-BMAed samples.

ening in $\mathrm{Al}$ matrix and the dispersion hardening by the submicron silicon particles.

As shown in Fig. 4, at higher number of BMA cycles, the effectiveness of the refining deteriorates. Larger and longer Si particles are more likely to crack. ${ }^{11)}$ At higher number of BMA cycle when the materials contain smaller and rounder morphology, the effectiveness of refining Si particles is less. Therefore, the first 500 cycles is chosen for this process. Further consolidation and mechanical testing were done on materials produced by BMA up to 500 cycles.

\subsection{Properties of after forging billet}

Figure 6 shows microstructure of Al-12 mass\%Si alloy billets produced by different number of BMA cycles, preheat-

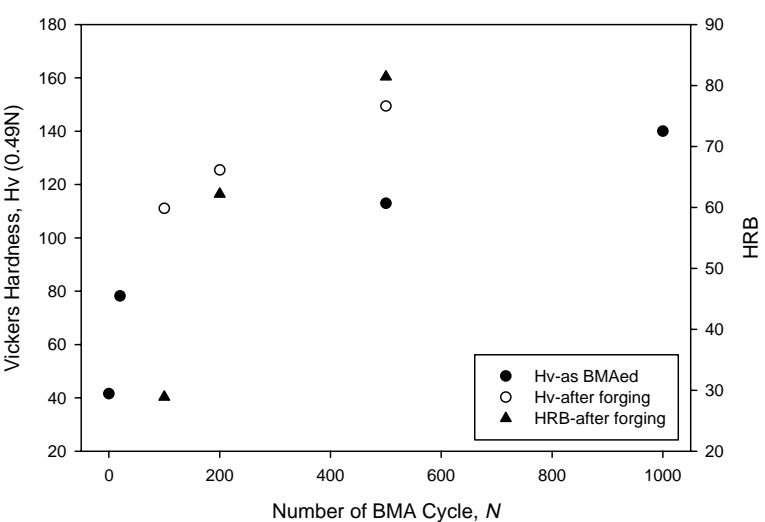

Fig. 5 Vickers hardness and Rockwell hardness of as-BMAed and after forging samples.
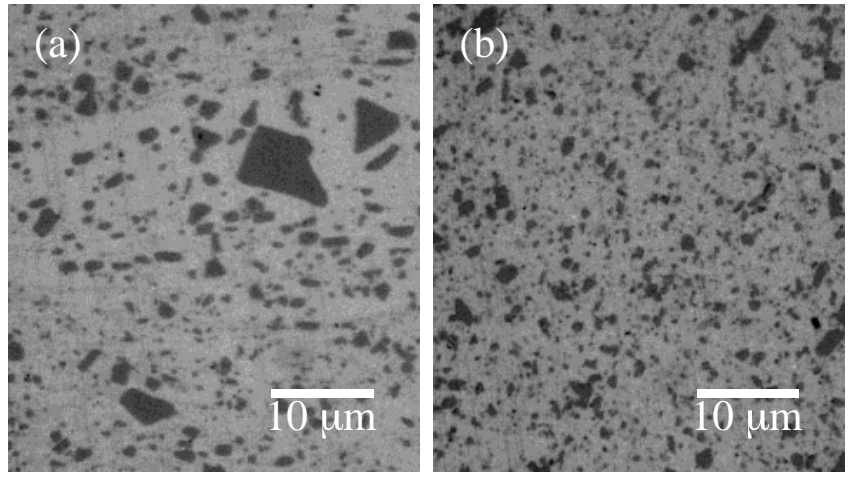

Fig. 6 Microstructure of Al-12 mass\%Si alloy after BMA, preheating at $773 \mathrm{~K}$ for $10 \mathrm{~min}$, and forging under $816 \mathrm{MPa}$. (a) BMA 100 cycles and (b) BMA 500 cycles. 


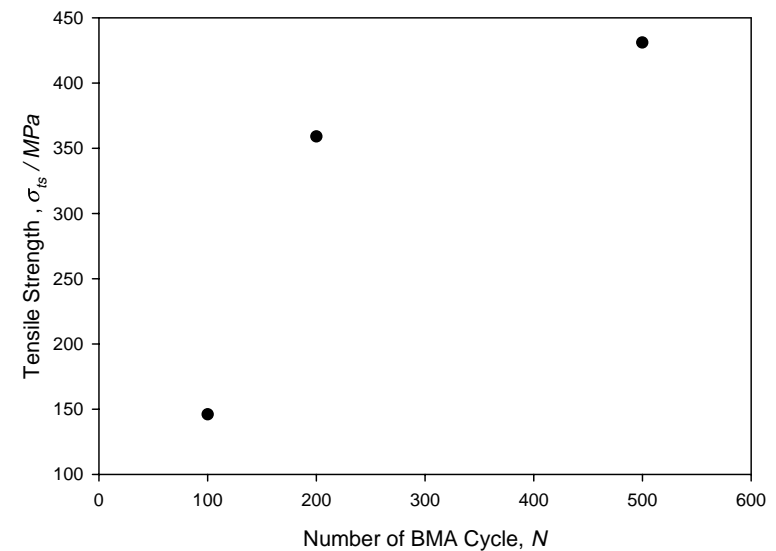

Fig. 7 Tensile strength of Al-12 mass $\%$ Si alloy produced by BMA, preheating at $773 \mathrm{~K}$ for $10 \mathrm{~min}$ and forging under $816 \mathrm{MPa}$.

Table 1 Mechanical properties of $\mathrm{Al}-12$ mass $\%$ Si produced by different routes.

\begin{tabular}{lccc}
\hline $\begin{array}{c}\text { Material } \\
(\text { Al-12 mass\%Si alloy })\end{array}$ & $\begin{array}{c}\text { Hv } \\
(0.49 \mathrm{~N})\end{array}$ & $\begin{array}{c}\text { Macro } \\
\text { hardness }\end{array}$ & $\begin{array}{c}\text { Tensile } \\
\text { strength } \\
(\mathrm{MPa})\end{array}$ \\
\hline BMA 100 cycles & 111 & $29 \mathrm{HRB}$ & 146 \\
BMA 200 cycles & 125 & $62 \mathrm{HRB}$ & 359 \\
BMA 500 cycles & 149 & $81 \mathrm{HRB}$ & 431 \\
P/M (69 $\mu \mathrm{m})$ & 101 & $72 \mathrm{HRB}$ & 387 \\
As cast $(\mathrm{AC3A})$ & - & $0 \mathrm{HRB}$ & 180 \\
& & $46 \mathrm{HRF}$ & \\
\hline
\end{tabular}

ing at $773 \mathrm{~K}$ for $10 \mathrm{~min}$, and forging. Microstructure of the forged billets show refined $\mathrm{Si}$ particles in $\mathrm{Al}$ matrix without any pores, indicating full density obtained. Short heating time during preheating is necessary for maintain work hardening and refinement of phases, while longer time is necessary for thorough heating, debinding the paraffin lubrication, and possibly sintering before forging. For all the preheating conditions, coarsening of Si particles in the alloys is not observed. This can be seen by the almost identical microstructure of the alloy before and after preheating and forging in Fig. 3 and Fig. 6. Figure 5 shows that microhardness of the billet increases after forging due to additional plastic deformation applied during forging.

Figure 7 shows tensile strength of the produced material. All billets were subjected to preheating at $773 \mathrm{~K}$ for $10 \mathrm{~min}$. The strength of the alloy depends on the number of BMA cycle. Rockwell hardness of the produced alloy in Fig. 5 also follows the same trend. The higher number of cycles may provide greater amount of plastic deformation in Al matrix and finer Si particle; hence, the higher tensile strength alloy was obtained. For BMA 500 cycle billet, tensile strength reaches $431 \mathrm{MPa}$, that is higher than those of cast alloy, $180 \mathrm{MPa}$, and those produced by powder metallurgy process, $387 \mathrm{MPa}$. Table 1 summarizes properties of $\mathrm{Al}-12$ mass $\% \mathrm{Si}$ produced by different processes.

The present study shows the possibility to design an alloy with specific properties through varying the number of BMA cycles. In addition to different mechanical properties obtained, the alloys with different Si particle size possess different wear property. ${ }^{12)}$ Thermal history of preheating before

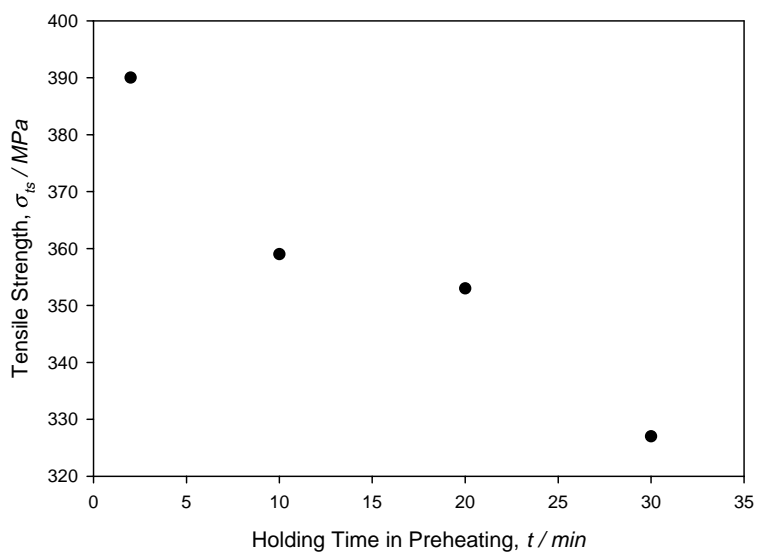

Fig. 8 Tensile strength of Al-12 mass\%Si alloy produced by BMA for 200 cycle, preheating at $773 \mathrm{~K}$ for various holding time, and forging under $816 \mathrm{MPa}$.

forging is another factor affecting the properties of the alloy. Figure 8 shows tensile strength of the alloy produced by BMA for 200 cycles and subjected to preheating at $773 \mathrm{~K}$ for different holding time. Long holding time causes softening of the alloy incurring lower tensile strength.

Figure 9 shows fracture surface of tensile specimen preheated for $2 \mathrm{~min}$ and $30 \mathrm{~min}$. Fracture mode is ductile in the Al matrix, indicating dimples, while cleavage brittle fracture occurs in the Si phase indicated by the ripple mark. Cohesion between $\mathrm{Si}$ particle and $\mathrm{Al}$ matrix is strong, since no particle pull out was observed. Dimple size in the sample heated for $30 \mathrm{~min}$ is larger and deeper than that of the sample heated for $2 \mathrm{~min}$. It is reported that $\mathrm{Al}-\mathrm{Si}$ alloy fails by cracks originated from larger Si particles. With increasing strain during tensile test, the number of damaged Si particle accumulates with extensive plastic flow in Al matrix until fracturing occurs. 6,11 )

\subsection{Energy consumption of BMA process}

Specific energy consumption of a process is of great concern when considering for industrial adoption. BMA is a repeated extrusion process at room temperature involving movement of punches in a closed die. Energy consumption of the process is monitored inline. A computer is connected to calculate instantaneous work done by the moving upper and lower punches. Work equals force times displacement:

$w_{1 \text {-cycle }}=\left\{\int_{\text {start }}^{\text {finish }} F d P\right\}_{\text {upper-punch }}+\left\{\int_{\text {start }}^{\text {finish }} F d P\right\}_{\text {lower-punch }}$

where $w_{1 \text {-cycle }}$ is work or energy consumed for each BMA cycle, $F$ is instantaneous punch load, and $d P$ is instantaneous punch displacement.

Figure 10 shows plots of energy consumption for each cycle of BMA up to 200 cycles. By average, the energy consumption is $13.6 \mathrm{~kJ} /$ cycle. The sharp drops of energy consumption at 60 and 120 cycles are due to liquid paraffin added into the die cavity. For the current setup, processing with $20 \times 10^{-3} \mathrm{Kg}$ of $\mathrm{Al}-12$ mass $\%$ Si chips for 200 cycles requires specific energy consumption of $136 \mathrm{MJ} / \mathrm{kg}$. From the view point of energy consumption, the merit of this process is justified since energy consumption for extracting aluminum from 

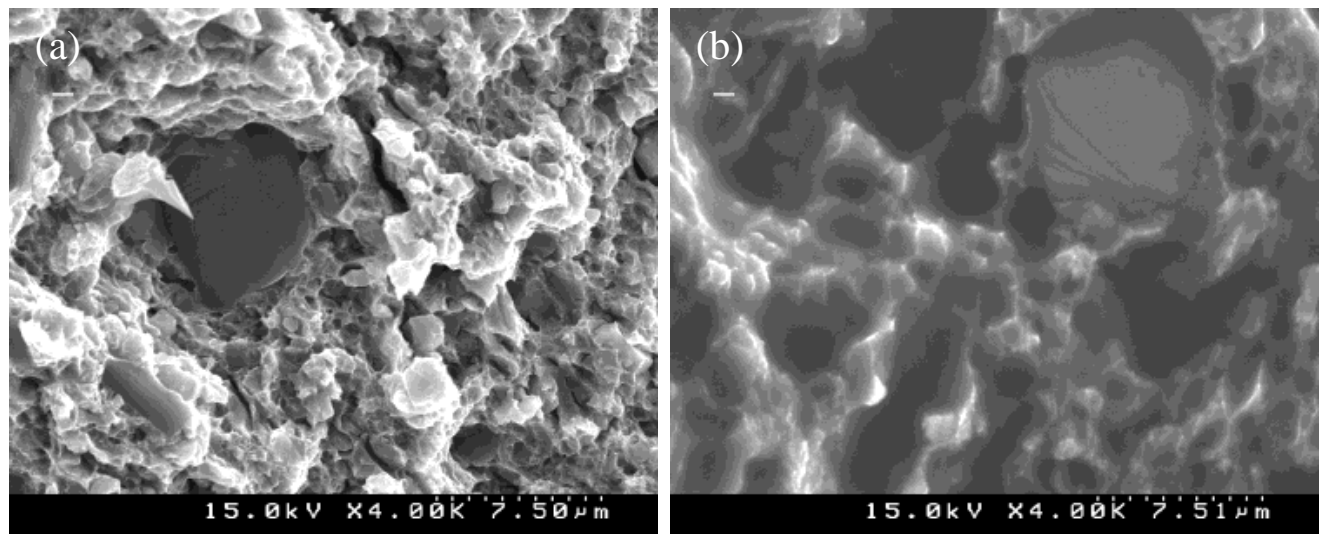

Fig. 9 Fracture surface of tensile specimen of Al-12 mass $\%$ Si alloy produced by BMA 200 cycles, preheated at $773 \mathrm{~K}$ for (a) 2 min and (b) $30 \mathrm{~min}$, and forged under $816 \mathrm{MPa}$.

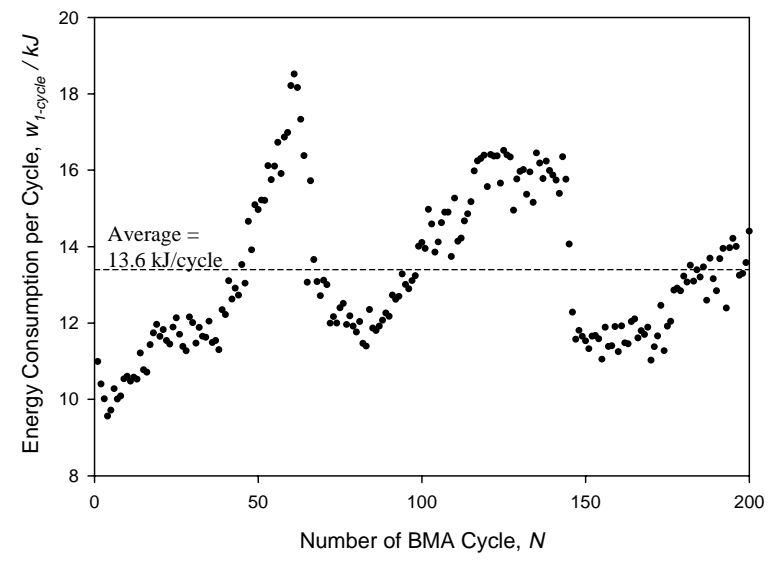

Fig. 10 Energy consumption per cycle of BMA process for producing Al-12 mass\% Si alloy from machined chips.

Table 2 Category of energy consumption of BMA process in producing Al-12 mass\% Si alloy from machined chips.

\begin{tabular}{lc}
\hline Category of energy & Amount (kJ/cycle) \\
\hline Plastic work to the material & 8.5 \\
Friction (scuffing, die wear, noise, etc.) & Not known, but minimal \\
Heat (from friction and plastic work) & $\sim 0.6$ \\
Moving the punches and machine parts & 4.5 \\
\hline
\end{tabular}

bauxite ore is $170 \mathrm{MJ} / \mathrm{kg} .{ }^{13)}$ Although energy consumption in melting of scrap, atomizing and cold compaction of $\mathrm{Al}-$ 17 mass $\%$ Si alloy by powder metallurgy route is $16.4 \mathrm{MJ} / \mathrm{kg}$, BMA process is much simpler than $\mathrm{P} / \mathrm{M}$ route which has several steps. ${ }^{3)}$ The energy consumed during BMA process can be categorized as in Table 2. The actual amount of energy for plastic deformation is $8.5 \mathrm{~kJ} /$ cycle, while the rest is wasted. Optimizing the process to industrial standard will enhance the efficiency of the process.

\section{Conclusion}

High-strength $\mathrm{Al}-12$ mass $\% \mathrm{Si}$ was developed from machined chips in the same composition. The chips were first subjected to repeated extrusion in BMA process and were further consolidated by preheating and forging. The produced material exhibited refined microstructure consisting of fine $\mathrm{Si}$ particles in work hardened Al matrix. Mechanical properties of the alloy were governed by the number of BMA cycles and preheating condition before forging. The Al-12 mass $\% \mathrm{Si}$ material, produced by BMA for 500 cycles, preheating at $773 \mathrm{~K}$ for $10 \mathrm{~min}$ and forging under $816 \mathrm{MPa}$, showed $431 \mathrm{MPa}$ in tensile strength. This is a recycle processing in solid state at room temperature. Therefore, problems usually encounter during melting in typical recycling process such as high energy consumption, melt loss, skim and oxide formation can be avoided. In the present study, for BMA 200 cycle, specific energy consumption is $136 \mathrm{MJ} / \mathrm{kg}$.

\section{REFERENCES}

1) D. V. Neff: ASM Handbook v.2, (ASM International, Ohio, 1990) pp. 1205-1213.

2) J. Gronostajski and A. Matuszak: J. Mat. Proc. Tech. 92-93 (1999) 3541.

3) T. Aizawa, T. Luangvaranunt and K. Kondoh: Proc. COM-2000, ed. by $\mathrm{H}$. Mostaghaci (Canandian Institute of Mining, Metallurgy, and Petroleum, 2000) pp. 273-288.

4) T. Aizawa, K. Tatsuzawa and J. Kihara: J. Fac. Eng. Univ. Tokyo XLII (1994) 261-279.

5) O. Kobayashi, T. Aizawa and J. Kihara: Mater. Trans., JIM 37 (1996) 1497-1504

6) A. Mocellin, Y. Brechet and R. Fougeres: Acta. Metallur. Mater. 43 (1995) 1135-1140.

7) J. Yeh, S. Yuan and C. Peng: Mater. Sci. Eng. A 252 (1998) 212-221.

8) M. F. Ashby: Philos. Mag. 21 (1970) 399-424.

9) M. Kouzeli and A. Mortensen: Acta. Mater. 50 (2002) 39-51.

10) G. E. Dieter: Mechanical Metallurgy, (McGraw-Hill, New York, 1986) pp. 217-219.

11) C. H. Caceres and J. R. Griffiths: Acta. Mater. 44 (1996) 25-33.

12) B. K. Prasad, K. Venkateswarlu, O. P. Modi, A. K. Jha, S. Das, R. Dasgupta and A. H. Yegneswaran: Metall. Mater. Tran. A 29 (1998) $2747-2752$.

13) H. A. Øye, N. Mason, R. D. Peterson, N. E. Richards, E. L. Rooy, F. J. Stevens McFadden, R. D. Zabreznik, F. S. Williams and R. B. Wagstaff: JOM Feb (1999) 29-42. 